\title{
Alternating current welding using four quadrant switches
}

\author{
A. Navarro-Crespin, Student Member, IEEE, Rosario Casanueva, Member, IEEE, and Francisco J. Azcondo, Senior \\ Member, IEEE \\ Dept. Electronics Technology, Systems and Automation Engineering. \\ University of Cantabria \\ Santander. Cantabria. Spain. \\ Email: anavarro@teisa.unican.es
}

\begin{abstract}
Welding metals such as aluminum and magnesium requires $\mathrm{AC}$ current. This work proposes a novel control strategy for a high-frequency rectifier built with four quadrant switches (4QSW) to transform high frequency $\mathrm{AC}$ current $(125 \mathrm{kHz})$ into the welding arc bipolar current, controlled in amplitude, frequency and even DC offset. The rectifier is connected to the output of a resonant inverter to achieve positive and negative polarity discharges both voltage and current by operating in two quadrants, i.e. positive and negative. As long as the input power to the converter is supplied by a current source, the typical dead-time set to avoid short circuit conditions jeopardize the safe operation of the switches. A field-programmable gate array (FPGA) is selected to implement the digital control due to its high resolution for the purpose to adapt the $4 \mathrm{QSW}$ 's drive signals without dead-time in the most accurate manner.
\end{abstract}

Keywords-AC welding, Four Quadrant Switch, Resonant Converters, Syncronous Rectification.

\section{INTRODUCTION}

Most of the arc welding processes are performed with direct current (DC), however some metals such as aluminum or magnesium when exposed to the air, rapidly form an oxide layer around $0.1 \mu \mathrm{m}$ thick. The melting point of this oxide skin is around $2000^{\circ} \mathrm{C}$, whereas aluminum and magnesium melt at approximately $650^{\circ} \mathrm{C}$. This difference in melting points makes these metals to melt, while oxide film does not. Therefore, the welding join will not be feasible. The removal of the oxide layer can be carried out mechanically, chemically or with alternating current (AC). This research is focused on the AC method.

Figure 1 represents the $\mathrm{AC}$ welding process. While the arc voltage and current are positive a cleaning effect occurs (Fig. 1a) while a melting process happens during the negative wave (Fig. 1b). When the polarity changes at low time derivative of current $(\mathrm{di} / \mathrm{dt})$, the arc welding becomes unstable. Then, for sinusoidal current generators, a high frequency is needed to stabilize the arc welding [1]. In this work, the bipolar rectifier is designed to leverage the high frequency input current source and achieve a steep di/dt at the output when a polarity change is programmed. The target output current of the welding power supply has a waveform as shown in Fig. 1c. Depending on the type of oxide, the pulse width (freqAC) and the duty cycle $(d)$ of the AC current waveform are adjusted to achieve either more cleaning action or higher penetration [2].

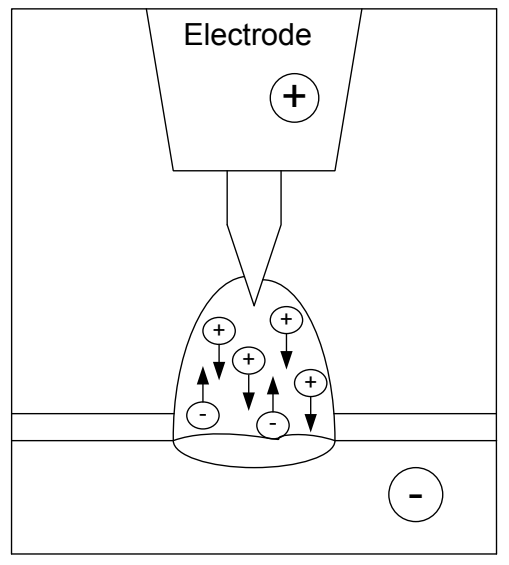

a)

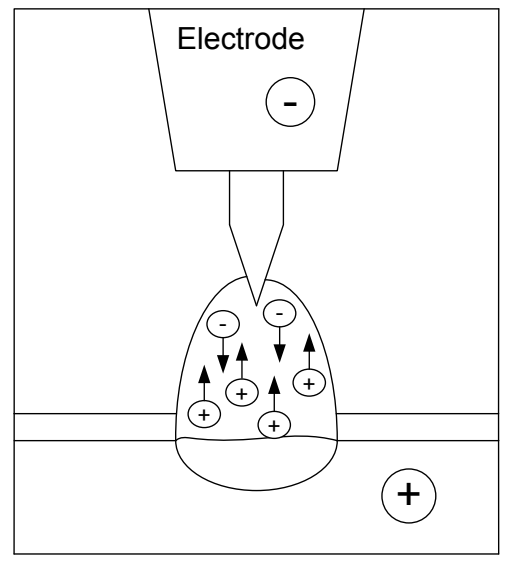

b)

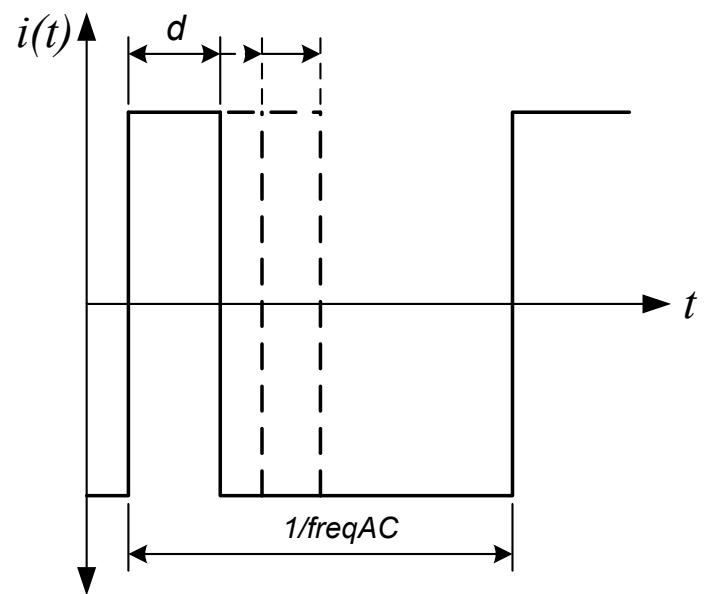

c)

Fig. 1. AC welding process: a) cleaning, b) melting, and c) welding current envelope waveform. 


\section{OBJECTIVES}

Resonant converters are suitable for applications where electrical discharges occur, e.g. discharge lamps, EDM (Electro Discharge Machining), ozone generation, induction heating, and welding [3-6].

In previous works [7-8], a DC welding power supply based on resonant converters has been developed. In order to adapt the power converter to $\mathrm{AC}$ requirements, the output stage (rectifier) has been replaced by a two level converter. This transforms the inverter output current to output AC current with a selected frequency (from low frequency up to $125 \mathrm{kHz}$ ).

The resonant inverter is designed as a current source hence, the short-circuit load condition leads to safe operation. Dead-times and overlap times in the drive signals of the four quadrants synchronous switches (4QSW) lead to an destructive voltage spikes and undesired conduction of the body diodes, respectively.

The proposed control algorithm generates two complementary signals without dead-time in order to drive the 4QSW's. It is necessary to synchronize the switches and the output current of the transformer. The current in the primary side of the transformer presents a phase-delay with respect the voltage that depends on the output load (arc between the electrode and material to be welded) and the required welding current.

Figure 2 shows the block diagram of the converter control circuit, where the signal Count represents the digital acquisition of the phase-difference between current and voltage on primary side, measured by the block Zero crossing, which captures the time difference between polarity changes of the input voltage of the resonant circuit and its output current. The measured delay is modified by the constant $K$, which denotes the time needed to adapt the signals to the proper values. Thereby, $\beta$ is the phase command used to generate the signal to drive the 4QSW's. This phase control has a predictive nature because the phase-lag computed in one period is applied in the next period to achieve the desired switching times. The result is a correct synchronization of the gate signals of the 4QSW's with the transformer secondary current.

Control parameters of the output current for AC welding are freq $A C$ and duty cycle $(d)$, where freq $A C$ is used to select the frequency of the AC output current, from units of $\mathrm{Hz}$ up to $125 \mathrm{kHz}$, which is the switching frequency of the resonant inverter stage, and $d$ denotes the pulsewidth of the wave cycle as shown in Fig. 1c.

\section{Secondary side}

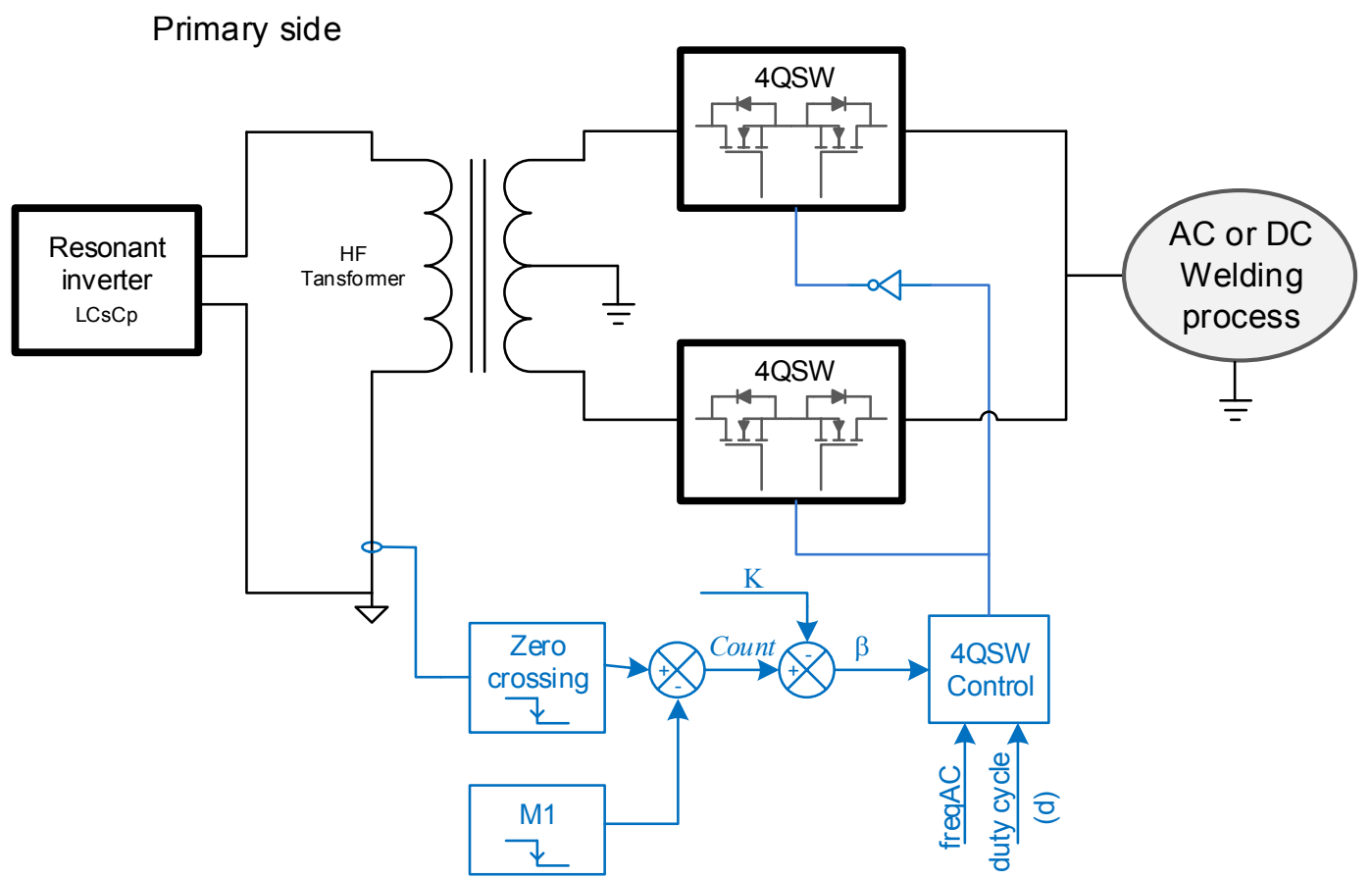

Fig. 2. Block diagram of the converter with $4 \mathrm{QSW}$. 


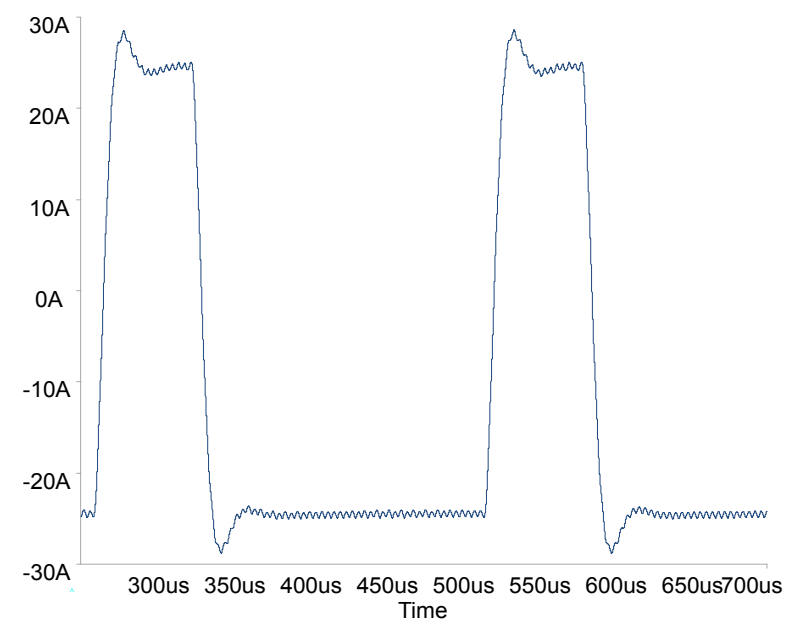

a)

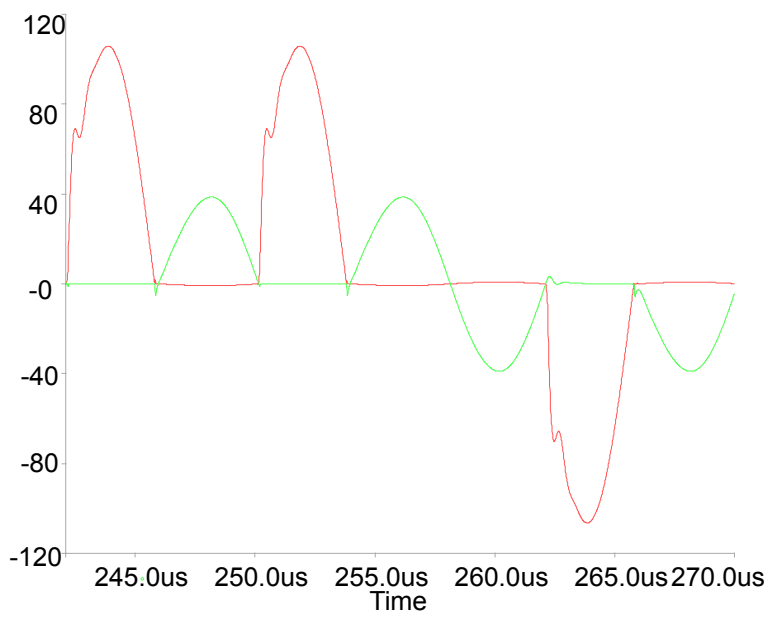

b)

Fig. 3. AC welding: simulated a) output current and b) voltage (red) and current (green) in a $4 \mathrm{QSW}$.

Figure 3a shows the output current in a PSpice simulation where freqAC $=3.9 \mathrm{kHz}$ and $d=25 \%$. Also Fig. $3 \mathrm{~b}$ shows voltage and current in a 4 QSW working in both quadrants providing a polarity change in the output current. The zero crossing is correctly synchronized and switching losses in the 4QSW are minimal because the switching events occur at zero voltage and current due to the sinusoidal shape of the input current and the right synchronization of the gate signals. On the other hand, conduction losses on each 4QSW are:

$$
P_{4 Q S W}=2 R_{d s(o n)} I_{o, r m s}^{2}
$$

\section{EXPERIMENTAL RESULTS}

A first verification of the proposal has been obtained with a prototype in nominal condition of load (resistor as load). The selected power MOSFETs to build the 4QSW are IRFS4115 $\left(V_{D S S}=150 \mathrm{~V}, I_{D}=105 \mathrm{~A}, R_{D S(o n)}=10 \mathrm{~m} \Omega\right)$. The nominal load resistance is $1 \Omega$.

Figure 4 shows the experimental waveforms of the four quadrant switches operation. The output current waveforms are shown in: Fig. $4 \mathrm{a}$ with freq $A C=20 \mathrm{kHz}$ and $d=66 \%$, Fig. $4 \mathrm{~b}$, with freqAC $=2 \mathrm{kHz}$ and $d=75 \%$ and Fig. $4 \mathrm{c}$ with freq $A C$ $=200 \mathrm{~Hz}$ and $d=25 \%$. Also, Fig. 4d shows the detailed voltage and current in one of the 4QSW, allowing a polarity change in the output current. It can be observed the proper synchronization of the ON and OFF times with the zero crossing of the current, achieving switching transients with minimal losses.

The proposal has also been verified in arc welding operations. The manual TIG welding process is performed using a $1.6 \mathrm{~mm}$ diameter $2 \%$ thoriated tungsten electrode and the base metal pieces are aluminum plates. The shielding gas is pure argon and no filler metal is used during the welding experiments.

Figure 5 shows the output current waveform at a frequency freqAC $=200 \mathrm{~Hz}$ with different duty cycles, $d=25 \%, 50 \%$, $75 \%$. 


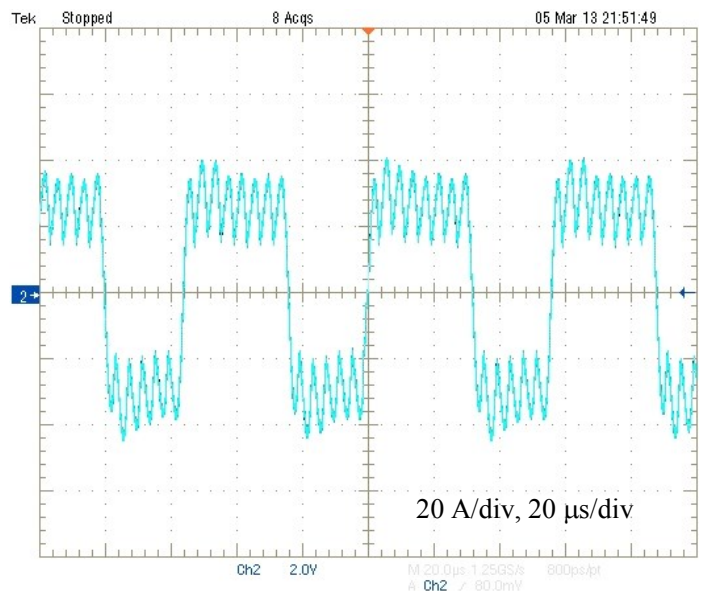

a)

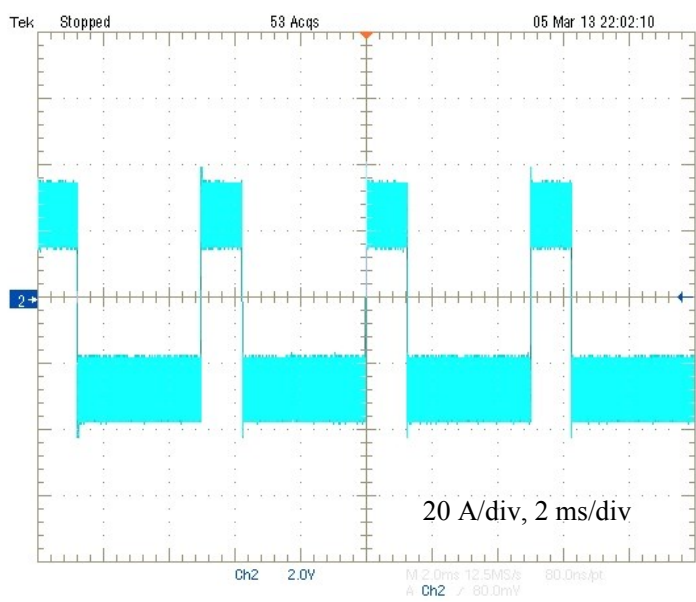

c)

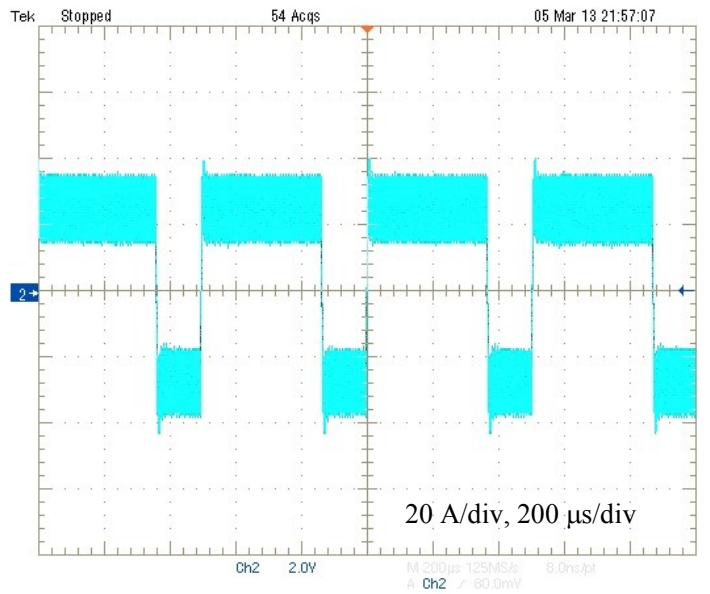

b)

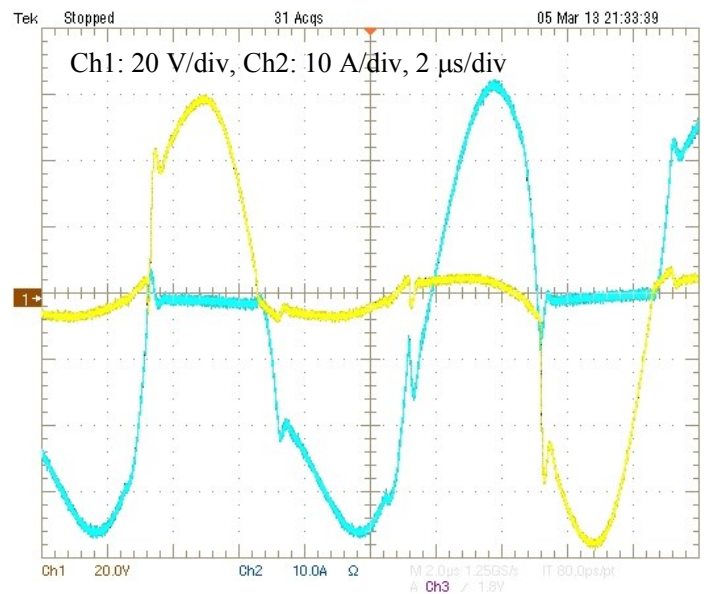

d)

Fig. 4. AC current: a) freq $A C=20 \mathrm{kHz}, d=66 \%$, b) freqAC $=2 \mathrm{kHz}, d=75 \%$, c) freqAC $=200 \mathrm{~Hz}, d=25 \%$ and d) voltage (yellow) and current (blue) in a 4QSW (drain-to-drain).

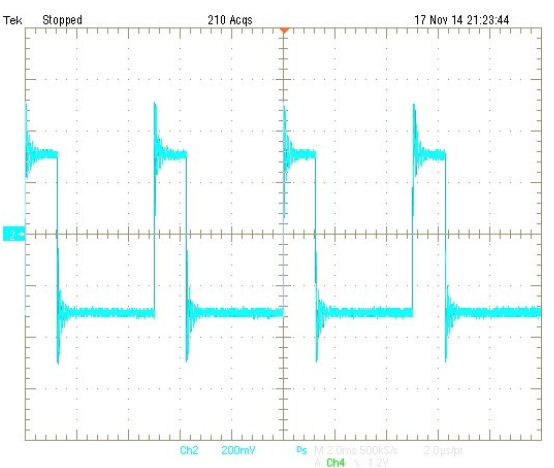

a)

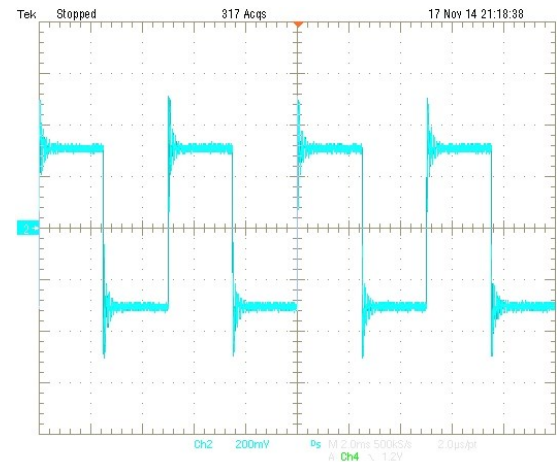

b)

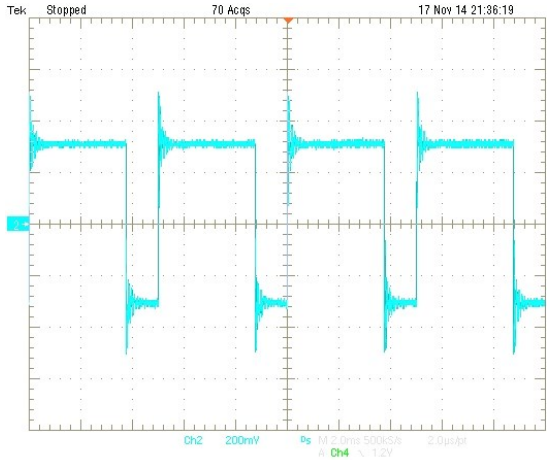

c)

Fig. 5. AC welding current at freqAC $=200 \mathrm{~Hz}$, a) $\mathrm{d}=25 \%$, b) $\mathrm{d}=50 \%$, and c) $\mathrm{d}=75 \%$. Ch2: $20 \mathrm{~A} / \mathrm{div}$; time scale: $2 \mathrm{~ms} / \mathrm{div}$.

\section{CONCLUSIONS}

A four quadrant switches converter and its control have been developed for an $\mathrm{AC}$ welding application. To obtain a very stable welding arc, the converter achieves a steep polarity change for a wide range of operation frequencies. Switching losses on 4QSW are minimized by the proper synchronization of the gate signals with the phase of the input current using a predictive digital algorithm. Output current is fully configurable from $\mathrm{DC}$ to $125 \mathrm{kHz}$ and the duty cycle from 0 to $100 \%$. 
The circuit has been experimentally verified in steady-state with the load emulated by resistances, achieving the expected behavior. Finally, arc welding operations have been performed to verify the proposal.

Future work is related to the digital control in overall system for providing a very stable arc welding in MIG process (Metal Inert Gas) where is necessary to regulate output voltage (Constant voltage operation) and the wire speed of the filler material.

\section{ACKNOWLEDGMENT}

This work was supported by FEDER and the Spanish Ministry of Science through the project CICYT-FEDERTEC2011- 23612: "Power conversion with new digital control techniques and soft-saturation magnetic cores".

\section{REFERENCES}

[1] Y.-K. Lo and J.-M. Wang "Current-regulated inverters with an output coupled inductor for AC arc welding machines", IET Power Electronics, vol. 1, pp. 445-454, Dec. 2008.
[2] Robert W. Messler, Jr. Principles of Welding. Processes, Physics, Chemistry, and Metallurgy. Wiley-VCH. 2004.

[3] X. Bonnin, J. Brandelero, N. Videau, H. Piquet, T. Meynard, "A High Voltage High Frequency Resonant Inverter for Supplying DBD Devices with Short Discharge Current Pulses," IEEE Transactions on Power Electronics, , vol. 29, pp. 4261-4269, Aug. 2014.

[4] O. Jimenez, O. Lucia, I. Urriza, L. Barragan, D. Navarro, "Power Measurement for Resonant Converters Applied to Induction Heating Applications", IEEE Transactions on Power Electronics, vol. 29, pp. 6779-6788, Dec. 2014.

[5] D. T. Rodrigues, J. A. Pomilio, "Resonant high-voltage supply for multiple paralleled loads with parameter equalization," 2011 Brazilian Power Electronics Conference (COBEP), pp. 390-396, Sept. 2011.

[6] J. Baizan, A. Navarro-Crespin, R. Casanueva, F. J: Azcondo, C. Branas, F. J. Diaz, "Converter with four quadrant switches for EDM applications," IEEE Transactions on Industry Applications, vol. 50, Nov.-Dec. 2014.

[7] R. Casanueva, F. J. Azcondo, F. J. Diaz and C. Branas, "TIG welding machines: a design for multiple two-phase resonant converter modules", IEEE Ind. Appl. Magazine, vol. 17, no. 5, pp. 53-58, Sept.-Oct. 2011.

[8] A. Navarro-Crespín, V. M. López, R. Casanueva, F. J. Azcondo, "Digital Control for an Arc Welding Machine based on Resonant Converters and Synchronous Rectification", IEEE Trans. Ind. Informatics, vol. 9, pp. 839-847, May 2013. 